\title{
AKTIVITAS ANTIOKSIDAN EKSTRAK RUMPUT LAUT Halimeda macroloba DARI PANTAI TELUK AWUR, JEPARA, JAWA TENGAH
}

\author{
Ahmad Fadhil Muzaki, Wilis Ari Setyati, Subagiyo, Rini Pramesti \\ Departemen IImu Kelautan Universitas Diponegoro Semarang \\ E-mail : AhmadFadhilMuzaky@gmail.com
}

Received August 2018 Accepted September 2018

\begin{abstract}
ABSTRAK
Antioksidan yang dihasilkan oleh tubuh berfungsi sebagai mekanisme perlindungan terhadap serangan radikal bebas memiliki jumlah yang terbatas. Antioksidan eksogen yang aman dan mudah diperoleh adalah antioksidan dari bahan alam seperti Halimeda macroloba yang mengandung senyawa bioaktif meliputi fenol, klorofil a dan $b$, serta karotenoid. Metode penelitian yang digunakan adalah deskriptif eksploratif. H. macroloba diperoleh dari Pantai Teluk Awur - Jepara dicuci bersih dengan air tawar dan diblender. Sampel dimaserasi pada pelarut metanol, etil asetat, dan n-heksan, serta diuapkan dengan rotary evaporator. Aktivitas antioksidan ditentukan dari nilai $I_{50}$. Nilai ini diperoleh dari persamaan kurva regresi linier pada nilai inhibisi yang terdeteksi dari nilai absorbansi DPPH murni terhadap pengaruh ekstrak $H$. macroloba yang diukur pada panjang gelombang $517 \mathrm{~nm}$. Kadar total fenol diuji menggunakan larutan Folin-Ciocalteu dengan asam galat sebagai larutan standar yang diukur pada panjang gelombang $725 \mathrm{~nm}$. Kadar klorofil a, b, dan karotenoid diukur pada panjang gelombang 663 $\mathrm{nm}, 646 \mathrm{~nm}$, dan $470 \mathrm{~nm}$. Hasil penelitian menunjukkan nilai IC $\mathrm{I}_{50}$ ekstrak metanol sebesar 38,57 ppm, etil asetat 1567,27 ppm dan n-heksan 259,34 ppm. Kadar total fenol pada masing-masing ekstrak adalah 87,10; 140,78 dan 102,24 (mg GAE/g berat basah sampel), kadar klorofil a sebesar 25,56; 28,44 dan 0,41 (mg/g berat basah sampel), kadar klorofil b sebesar 42,10; 41,94 dan 0,61 ( $\mathrm{mg} / \mathrm{g}$ berat basah sampel), dan kadar karotenoid sebesar 97,92; 85,68 dan 2,34 ( $\mu \mathrm{mol} / \mathrm{g}$ berat basah sampel). Nilai $\mathrm{IC}_{50}$ dari ekstrak metanol termasuk kategori aktivitas antioksidan sangat kuat sedangkan ekstrak etil asetat dan n-heksan termasuk kategori aktivitas antioksidan sangat lemah.
\end{abstract}

Kata kunci : H. macroloba, Antioksidan, DPPH 


\begin{abstract}
Antioxidant that produced by body that have a protect mecanism from free radicals attack which is totaly infinity. Safe antioxidant exogenous and easily obtained is antioxidant from natural such as Halimeda macroloba that contains bioactive compound include phenol, chlorophylls $a$ and $b$, and carotenoids. The method was used descriptively explorative. $H$. macroloba obtained from Teluk Awur Beach Jepara washed by freshwater and blended. Macerated sample singly on methanol, etil asetat, and $n$ heksan solvent, also evaporated with rotary evaporator. Antioxidant activity determined from value of $I C_{50} . I C_{50}$ obtained from linear regression curve equation from inhibisi value which detected by absorbance value of pure DPPH to extract Halimeda macroloba effect that measured by wave length $517 \mathrm{~nm}$. Total phenol content tested by the Folin-Ciocalteu solution with gallic acid as standard and measured at a wavelength of $725 \mathrm{~nm}$. The chlorophylls $a$ and $b$, and carotenoids content were measured at $a$ wavelength of $663 \mathrm{~nm}, 646 \mathrm{~nm}$, and $470 \mathrm{~nm}$. The results showed $1 C_{50}$ value of extract methanol was 38,57 ppm, ethyl acetat was 1567,27 ppm and $n$-hexane was $259,34 \mathrm{ppm}$. Total phenol content in each extract were 87,10; 140,78 and 102,24 (mg GAE/g wet weight sample), chlorophyll a content were 25,56; 28,44 and 0,41 ( $\mathrm{mg} / \mathrm{g}$ wet weight sample), chlorophyll b content were 42,10; 41,94 and 0,61 (mg/g wet weight sample), and carotenoids content were 97,92; 85,68 and 2,34 ( $\mu$ mol/g wet weight sample). $\quad I C_{50}$ value of methanol extracts categorized as very strong antioxidant activity, ethyl acetate and $n$-hexane extracts categorized as very weak antioxidant activity.
\end{abstract}

Keywords : H. macroloba, Antioxidant, DPPH

\title{
PENDAHULUAN
}

Radikal bebas merupakan senyawa kimia yang mempunyai satu atau lebih elektron tidak berpasangan yang dapat menyebabkan reaksi berantai (Badarinath et al., 2010). Reaksi berantai ini terjadi di dalam tubuh melalui proses metabolisme sel normal, peradangan dan adaya reaksi antara besi logam transisi dalam tubuh (Sayuti \& Yerina, 2015) serta terbentuk dari luar tubuh sebagai respons adanya sinar ultraviolet (UV), polusi lingkungan dan asap rokok (Wijaya, 1996). Radikal bebas didalam tubuh dapat menyebabkan pengerasan pembuluh jaringan, koroner, stroke, kanker, penyakit degeneratif seperti diabetes militus, inflamasi, arterosclerosis dan penuaan dini (Kang et al., 2010).

Antioksidan adalah senyawa yang mampu menginaktivasi berkembangnya reaksi oksidasi dengan cara mencegah terbentuknya radikal bebas (Winarsi, 2007). Antioksidan secara endogen dihasilkan tubuh dan secara eksogen berasal dari makanan (Stahl \& Sies, 2003). Berdasarkan sumbernya antioksidan eksogen dibagi dua yaitu antioksidan sintetik dan alami. Antioksidan sintetik memiliki batas penggunaan $0,02 \%$ 
dari lemak dan kurang aman bagi kesehatan karena bersifat karsinogen jika digunakan berlebihan (Fitri, 2013). Antioksidan alami memiliki keuntungan yaitu aman karena tidak terkontaminasi zat kimia (Septiana \& Asnani, 2013). Salah satu bahan alam yang dapat digunakan sebagai antioksidan adalah rumput laut (Nawaly et al., 2013).

Halimeda mempunyai senyawa polifenol bromat sederhana, senyawa flavonoid dan katekin yang memiliki aktivitas antioksidan karena mempunyai gugus fenol. Salah satu jenis Halimeda yang memiliki senyawa tersebut yaitu $H$. macroloba (Hsieh et al., 2002). Halimeda merupakan salah satu genus rumput laut dari divisi Chlorophyta yang berpotensi sebagai antioksidan alami. $H$. tuna yang diambil dari laut selatan India menunjukkan aktivitas antioksidan dengan nilai $\mathrm{IC}_{50} 0,2 \mathrm{ppm}$ (Devi et al., 2011). H. durvilae dan H. macroloba dari Sulawesi Utara yang diekstrak dengan pelarut metanol $70 \%$ mempunyai nilai $I_{50}$ sebesar 64,63 ppm dan 57,73 ppm (Sanger et al., 2013). Penelitian ini bertujuan untuk menentukan aktivitas antioksidan ekstrak rumput laut $H$. macroloba kandungan total fenol, klorofil a dan b, serta karotenoid.

\section{MATERI DAN METODE}

\section{Materi Penelitian}

Materi penelitian yang digunakan adalah rumput laut jenis Halimeda macroloba yang diambil dari Pantai Teluk Awur, Jepara, Jawa Tengah.

\section{Metode Penelitian}

Metode yang digunakan secara metode deskriptif eksploratif. Penelitian dilaksanakan di Laboratorium Terpadu Universitas Diponegoro dan Laboratorium Balai Pengujian dan Informasi Konstruksi (BPIK), Semarang. Penelitian terdiri dari 6 tahap yaitu : (1). Pengambilan sampel, (2). Preparasi sampel, (3). Ekstraksi sampel, (4). Uji aktivitas antioksidan, (5). Penentuan kadar total fenol, (6). Penentuan kadar klorofil a dan b, serta karotenoid.

\section{Pengambilan Sampel}

Sampel diambil saat pantai dalam keadaan surut secara purposive sampling (Sugiyono, 2005). Sampel yang diperoleh dicuci menggunakan air tawar untuk menghilangkan kotoran dan epifit yang menempel yang selanjutnya ditiriskan menggunakan kain lalu disimpan dalam coolbox yang berisi es.

\section{Preparasi Sampel}

Kadar air dianalisis mengacu pada prosedur yang dilakukan Widayanti et al. (2013). Cawan kosong dipanaskan dalam oven selama 1 
jam pada suhu $105{ }^{\circ} \mathrm{C}$ kemudian didinginkan dalam desikator selama 30 menit, lalu ditimbang hingga beratnya konstan. Sampel segar sebanyak 2 gram diletakkan dalam cawan dan dikeringkan dengan oven pada suhu 100-105 ${ }^{0} \mathrm{C}$ selama 5 jam atau sampai beratnya konstan. Proses selanjutnya didinginkan dalam desikator selama 30 menit dan ditimbang. Kadar air dihitung menggunakan rumus:

Kadar air $(\%)=\frac{(\text { Berat cawan+sampel basah })-(\text { berat cawan+sampel kering })}{(\text { Berat cawan+sampel basah })-(\text { Berat cawan kosong })} \times \quad 100 \%$

\section{Ekstraksi Sampel}

Proses ekstraksi sampel menurut Andayani et al. (2008) yang telah dimodifikasi. Pada proses maserasi meliputi: perbandingan sampel dan pelarut serta waktu maserasi. Maserasi dilakukan secara tunggal, yaitu satu sampel menggunakan satu pelarut dengan kepolaran yang berbeda. Pelarut yang digunakan adalah metanol (polar), etil asetat (semi polar), dan n-heksan (non-polar). Hal ini bertujuan untuk mengetahui aktivitas antioksidan dari masing-masing pelarut. Sampel segar dibersihkan menggunakan air tawar kemudian diblender dan ditimbang sebanyak 50 gram untuk masing-masing pelarut. Proses selanjutnya dimasukan ke dalam botol gelas yang berisi pelarut $400 \mathrm{ml}$ (perbandingan sampel dan pelarut $1: 8$ ) dan dimaserasi selama 24 jam pada suhu ruang $\pm 28^{\circ} \mathrm{C}$. Hasil maserasi disaring menggunakan kertas saring Whatman no. 42 sehingga diperoleh filtrat dan residu dari masing-masing pelarut. Residu dimaserasi kembali menggunakan pelarut baru selama 24 jam dan filtrat yang dihasilkan digabung kedalam botol yang sama dengan filtrat pertama. Filtrat dari setiap pelarut diuapkan dengan rotary evaporator pada suhu 40 ${ }^{0} \mathrm{C}$ sampai diperoleh ekstrak. Ekstrak yang dihasilkan dimasukkan ke dalam vial untuk dilakukan uji selanjutnya. Perhitungan rendemen menggunakan rumus:

$$
\% \text { Rendemen }=\frac{\text { Jumlah berat ekstrak berupa pasta }(g)}{\text { Jumlah berat awal }(g)} \times 100 \%
$$

Keterangan :

Berat ekstrak $=($ Berat vial + ekstrak $)-$ berat vial kosong $(g)$

\section{Uji Aktivitas Antioksidan}

Aktivitas antioksidan berdasarkan pada kemampuan ekstrak dalam mereduksi DPPH (1,1 - diphenyl -2- picry/hidrazy). Uji ini menggunakan metode spektofotometri seperti yang dilakukan oleh Leong \& Shui (2002); Miliauskas et al. (2004) yang telah dimodifikasi konsentrasinya. Konsentrasi ekstrak yang digunakan sebesar 50 ppm, 100 ppm, 150 ppm, 200 ppm, dan 250 ppm. Hasil pengenceran ekstrak masing-masing diambil $1,5 \mathrm{ml}$ dan ditambahkan $3 \mathrm{ml}$ larutan DPPH 0,1 mM. Campuran reaksi dari larutan tersebut diinkubasi dalam ruang gelap selama 30 menit, 
kemudian diukur nilai absorbansinya dengan menggunakan spektofotometer UV-Vis pada panjang gelombang $517 \mathrm{~nm}$.

Nilai presentase penghambat aktivitas radikal bebas dihitung dengan menggunakan rumus:

$$
\text { Penghambatan radikal bebas }(\%)=\frac{(A-B)}{A} \times 100
$$

Keterangan:
$\mathrm{A}=$ Absorbansi larutan DPPH
$\mathrm{B}=$ Absorbansi dari campuran larutan sampel dan $\mathrm{DPPH}$

Nilai penghambat radikal bebas DPPH (\%) digunakan untuk menentukan nilai $\mathrm{IC}_{50}$. Nilai ini dihitung menggunakan persamaan regresi yang diperoleh dari hubungan antara konsentrasi sampel dengan presentase penghambatan radikal bebas (\%).

\section{Penentuan Kadar Total Fenol}

Kadar total fenol diukur dengan metode yang mengacu pada Yangthong et al. (2009); Sharma et al. (2011) dalam Santoso et al. (2012). Ekstrak dengan berat $5 \mathrm{mg}$ dilarutkan dalam $2 \mathrm{ml}$ etanol p.a lalu ditambahkan $5 \mathrm{ml}$ aquades dan $0,5 \mathrm{ml}$ reagen Folin-Ciocalteu $50 \%$. Campuran diinkubasi selama 5 menit dan ditambahkan $1 \mathrm{ml} \mathrm{Na}_{2} \mathrm{CO}_{3} 5 \%$. Larutan dihomogenkan lalu diinkubasi dalam kondisi gelap selama satu jam. Nilai absorbansi larutan diukur dengan spektofotometer UV-Vis pada panjang gelombang $725 \mathrm{~nm}$.

Asam galat yang digunakan sebagai standar dengan konsentrasi 0 , $10,20,30,40,50 \mathrm{mg} / \mathrm{l}$. Kurva kalibrasi asam galat digunakan untuk menentukan kadar senyawa fenol yang terkandung dalam sampel melalui persamaan regresi dan nilai total fenol dinyatakan dalam mg Galic Acid Equivalent (GAE)/ $1000 \mathrm{~g}$ ekstrak.

$$
\text { Total fenol }=\frac{(a \times V) / \mathbf{1 0 0 0}}{G}
$$

Keterangan :

a $\quad=$ Konsentrasi asam galat dalam sampel uji

$\mathrm{V} \quad=$ Volume total larutan uji $(\mathrm{ml})$

$\mathrm{G} \quad=$ Berat ekstrak yang digunakan $(\mathrm{g})$

1000 = Faktor konversi terhadap volume total larutan (ml)

\section{Penentuan Kadar Klorofil a dan b, serta Karotenoid}

Pengukuran klorofil a, klorofil b dan karotenoid didasarkan pada Lichtenthaler (1987). Ekstrak metanol, etil asetat, dan n-heksan ditimbang, kemudian dilarutkan aseton p.a sesuai dengan konsentrasi (5 mg ekstrak / 
$5 \mathrm{~mL}$ aseton p.a). Masing - masing konsentrasi diukur absorbansinya pada panjang gelombang $646 \mathrm{~nm}, 663 \mathrm{~nm}$, dan $470 \mathrm{~nm}$.

Kadar klorofil dan karotenoid dihitung berdasarkan rumus sebagai berikut :

i. Klorofil a mg/g sampel $(\mathrm{Ca}) \quad=12,21 \times \mathrm{A} 663-2,81 \times \mathrm{A} 646$

ii. Klorofil b $\mathrm{mg} / \mathrm{g}$ sampel $(\mathrm{Cb}) \quad=20,13 \times \mathrm{A} 663-5,03 \times \mathrm{A663}$

iii. Karotenoid $\mu \mathrm{mol} / \mathrm{g}$ sampel $(\mathrm{Cx}+\mathrm{C})=$

$$
\frac{(A 470+0,114 \times A 663-0,638 \times A 646) \times V \times 1000}{112,5 \times 0,1 \times 10}
$$

Keterangan:

A663 = Nilai absorbansi panjang gelombang $663 \mathrm{~nm}$

A664 = Nilai absorbansi panjang gelombang $646 \mathrm{~nm}$

A470 = Nilai absorbansi panjang gelombang $470 \mathrm{~nm}$

\section{HASIL DAN PEMBAHASAN}

Ciri morfologi dari Halimeda macroloba (lihat Gambar 1) yaitu tumbuhan berbentuk thalus berwarna hijau, segmen berbentuk kipas, lebar dan tebal. Bagian pinggirnya bergelombang, percabangan utama trichotomus, Holdfast berbentuk cakram dan seperti ubi (Atmadja et al. (1996).

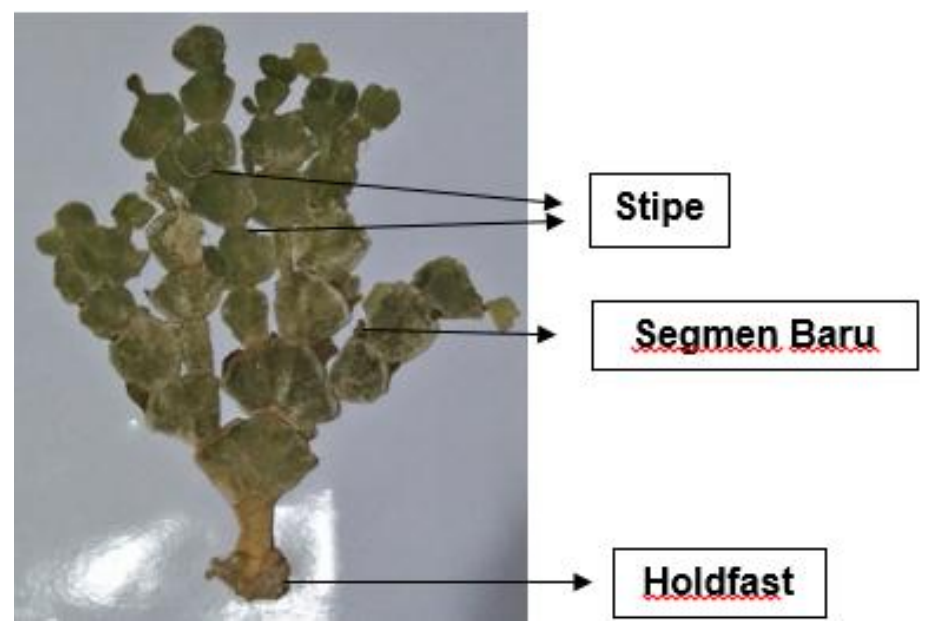

Gambar 1. Bagian-bagian talus H. macroloba

Sampel diekstraksi dalam keadaan segar, karena komponen aktif tidak tahan panas terhadap suhu tinggi selama pengeringan (Djapiala et al., 2011). Sampel dimaserasi dengan pelarut metanol (polar), etil asetat (semi polar), dan n-heksan (non-polar). Hasil ekstraksi dapat dilihat pada Tabel 1. 
Tabel 1. Hasil ekstraksi H. macroloba

\begin{tabular}{lllll}
\hline Pelarut & Bentuk & Warna & $\begin{array}{l}\text { Berat Ekstrak } \\
(\mathrm{gr})\end{array}$ & $\begin{array}{l}\text { Rendemen } \\
\text { Ekstrak }(\%)\end{array}$ \\
\hline Metanol & Padat & Hijau Pekat & 0,17 & 0,34 \\
Etil asetat & Pasta & $\begin{array}{l}\text { Coklat } \\
\text { Kekuningan }\end{array}$ & 0,14 & 0,28 \\
n-heksan & Cair & Kuning & 0,02 & 0,04 \\
\hline
\end{tabular}

Hasil penelitian tentang rendemen tertinggi diperoleh ekstrak metanol yaitu $0,34 \%$, ekstrak etil asetat dan $n$-heksan secara berurutan yaitu $0,28 \%$ dan $0,04 \%$. Nilai rendemen berkurang dengan menurunnya tingkat kepolaran. Hal ini diduga sampel memiliki senyawa bioaktif yang bersifat polar. Sarastani et al. (2002), menyatakan pelarut dapat melarutkan senyawa dengan kepolaran yang sama dan dapat mempengaruhi sifat fisiokimia ekstrak yang dihasilkan. Secara visual ekstrak metanol berwarna hijau pekat, ekstrak etil asetat berwarna coklat kekuningan, dan n-heksan berwarna kuning. Warna hijau pekat diduga menunjukkan banyaknya kandungan klorofil dibanding pigmen yang lain. Warna coklat kekuningan sampai kuning diduga menunjukkan adanya kandungan karotenoid.

Aktivitas antioksidan ekstrak $\mathrm{H}$. macroloba ditentukan dari nilai $\mathrm{IC}_{50}$ yaitu besarnya konsentrasi larutan uji dalam meredam 50\% aktivitas radikal bebas $\mathrm{DPPH}$. Nilai $\mathrm{IC}_{50}$ dihitung dari persamaan regresi linier konsentrasi ekstrak terhadap tingkat inhibisi DPPH (Gambar 2.)

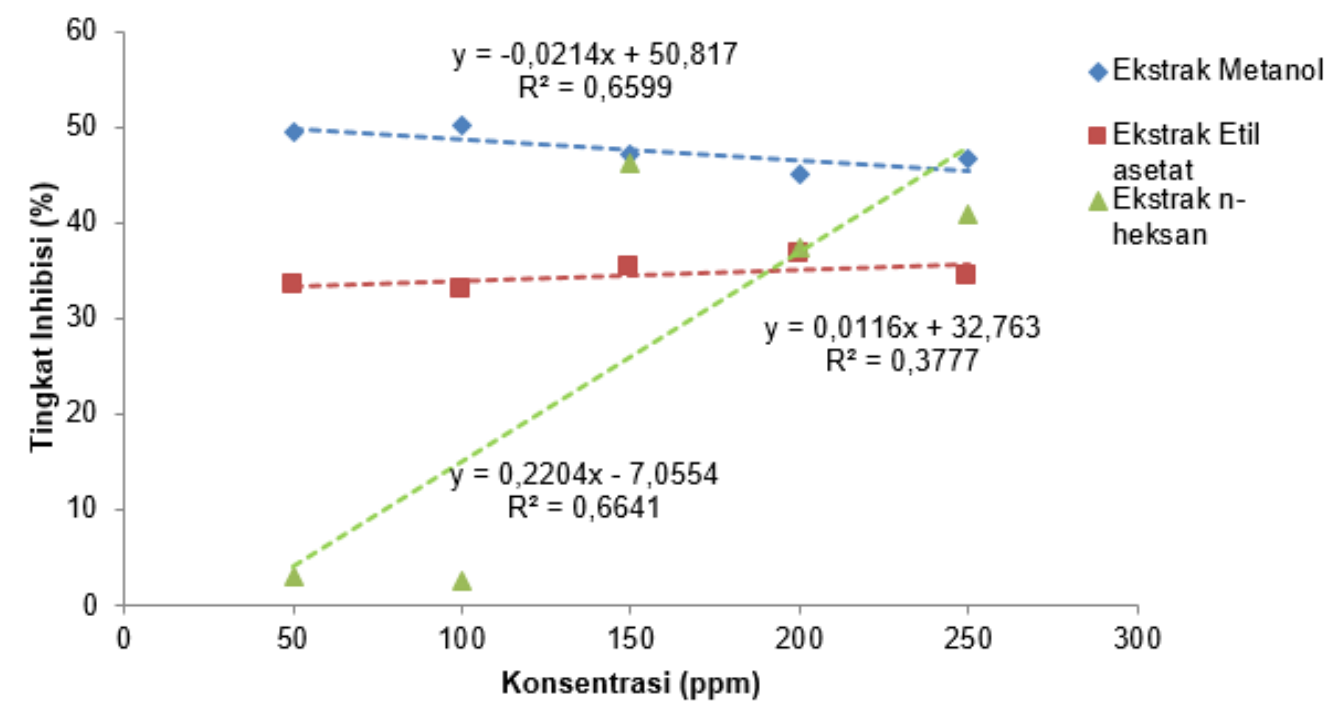

Gambar 2. Grafik Aktivitas Antioksidan Ekstrak H. macroloba 
Hasil penentuan aktivitas antioksidan meliputi nilai $I_{50}$, kadar totar fenol, klorofil a dan b, serta karotenoid ditampilkan pada Tabel 2.

Tabel 2. Nilai $I_{50}$, kadar total fenol, klorofil a dan $b$, serta karotenoid ekstrak H. macroloba.

\begin{tabular}{|c|c|c|c|c|c|}
\hline $\begin{array}{l}\text { Parameter } \\
\text { Uji }\end{array}$ & $\begin{array}{l}\text { Uji } \\
\text { DPPH } \\
\left(\mathrm{IC}_{50}\right) \\
(\mathrm{ppm})\end{array}$ & $\begin{array}{l}\text { Total } \\
\text { Fenol } \\
(\mathrm{mg} \\
\text { GAE/g) }\end{array}$ & $\begin{array}{l}\text { Klorofil a } \\
(\mathrm{mg} / \mathrm{g})\end{array}$ & $\begin{array}{l}\text { Klorofil } \\
\text { b } \\
(\mathrm{mg} / \mathrm{g})\end{array}$ & $\begin{array}{l}\text { Karotenoid } \\
(\mu \mathrm{mol} / \mathrm{g})\end{array}$ \\
\hline Metanol & 38,57 & 87,10 & 25,56 & 42,10 & 97,92 \\
\hline Etil asetat & $\begin{array}{l}1567,2 \\
7\end{array}$ & 140,78 & 28,44 & 41,94 & 85,68 \\
\hline n-heksan & 259,34 & 102,24 & 0,41 & 0,61 & 2,34 \\
\hline
\end{tabular}

Nilai $I_{50}$ pada ekstrak metanol 38,57 ppm dan tergolong antioksidan yang sangat kuat, ekstrak etil asetat dan n-heksan berturutturut memiliki nilai $I_{50}$ sebesar 1567,27 ppm dan 259,34 ppm dan tergolong sangat lemah (Mardawati et al., 2008). Ekstrak etil asetat dan nheksan tergolong sangat lemah, hal ini diduga sampel yang diuji berupa ekstrak kasar. Ditambahkan Wikanta et al. (2005), ekstrak kasar diduga mengandung senyawa-senyawa lain seperti garam, mineral, dan nutriennutrien lain yang dapat menghambat kerja senyawa antioksidan tersebut. Budhiyanti et al. (2012), menyatakan aktivitas antioksidan dan total fenol dari suatu sampel dipengaruhi oleh tipe pelarut, metode ekstraksi, musim, lokasi, dan jenis spesies. Sedangkan (Wirakusumah, 2007; Ndhalala et al., 2010) aktivitas antioksidan dipengaruhi oleh senyawa bioaktif seperti senyawa fenol dan pigmen (klorofil dan karotenoid). Kadar total fenol tertinggi diperoleh ekstrak etil asetat sebesar 140,78 mg GAE/g berat basah sampel. Senyawa fenol terbanyak tidak selalu terdapat dalam ekstrak polar, namun tergantung dari struktur senyawa fenol sehingga senyawa ini dapat larut dalam pelarut semi polar maupun non-polar (Sheikh et al., 2009). Lim et al. (2002), menyatakan korelasi antara kadar fenol dengan aktivitas antioksidan tidak selalu terjadi. Hal ini diduga terdapat senyawa lain dalam rumput laut yang dapat berperan dalam menyumbangkan aktivitas antioksidan. Rumput laut mengandung senyawa-senyawa lain seperti: agar-agar, porpiran, furcelaran, protein, lemak, kalsium, unsur mineral, klorofil dan karotenoid (Indriani \& Sumiarsih, 1997).

Ekstrak etil asetat mengandung klorofil a yang tertinggi sebesar $28,44 \mathrm{mg} / \mathrm{g}$ berat basah sampel dan ekstrak metanol mengandung klorofil b tertinggi sebesar $42,10 \mathrm{mg} / \mathrm{g}$ berat basah sampel. Młodzińska (2009), klorofil a bersifat kurang polar, sedangkan klorofil b bersifat polar. Pigmen lain yang berfungsi sebagai antioksidan adalah karotenoid. Hasil 
penelitian menunjukkan karotenoid terdapat disemua ekstrak pelarut baik polar, semi polar, dan non-polar. Ekstrak metanol mengandung karotenoid tertinggi sebesar $97,92 \mu \mathrm{mol} / \mathrm{g}$ berat basah sampel. Ekstrak $H$. macroloba diduga mengandung jenis karotenoid berupa xantofil. Jenis ini mudah larut dalam metanol. Pelarut polar dapat melarutkan karotenoid pada kelompok xantofil, karena xantofil mengandung gugus hidroksil yang bersifat polar (Munifah \& Likanta, 2006).

Berdasarkan hasil penelitian diduga senyawa karotenoid dan klorofil b berperan terhadap antioksidan karena aktivitas tertinggi diperoleh dari ekstrak metanol. Klorofil dapat mencegah proses oksidasi lipid dengan mekanisme pendonoran atom hidrogen, sehingga memutus rantai reaksi pembentukan radikal. Hidrogen yang didonorkan terletak pada gugus metal pada klorofil a atau gugus aldehid pada klorofil b (Marquez et al., 2005). Karotenoid sebagai antioksidan mampu melinungi sel dan organisme dengan meniadakan aktivitas radikal bebas. Penghambatan radikal bebas oleh karotenoid terutama dilakukan oleh $\beta$-karoten. Reaksi karotenoid terhadap radikal bebas ditunjukan oleh $\beta$-karoten yang bereaksi dengan radikal peroksil dapat mengakibatkan terbentuknya radikal ROO-Carotene (radikal ROO-CAR) dan terjadi delokasi elektron, sehingga elektron tersebar di seluruh struktur $\beta$-karoten. Radikal ROOCAR yang bereaksi dengan radikal ROO-CAR dapat membentuk $\beta$ karoten netral (Burton \& Inglod, 1984).

\section{KESIMPULAN}

Halimeda macroloba yang diambil dari Pantai Teluk Awur Jepara mempunyai aktivitas antioksidan yang sangat kuat pada ekstrak metanol dengan nilai $\mathrm{IC}_{50}$ sebesar 38,57 ppm.

\section{DAFTAR PUSTAKA}

Andayani, R., Lisawati, Y., dan Maimunah. 2008. Penentuan Aktivitas Antioksidan, Kadar Fenolat Total dan Likopen pada Buah Tomat (Solanum lycopersicum L). Jurnal Sains dan Teknologi Farmasi, 13(1): 1-9 hlm.

Atmadja, W.S., Kadi, A., Sulistijo, dan Satari, R. 1996. Pengenalan JenisJenis Rumput Laut Indonesia. PUSLITBANG OSEANOGRAFI LIPI, Indonesia, iii-iv hlm.

Badarinath, A.V., RAo, K.M., Chetty, C.M.S., and Ramkanth, S. 2010. A Review on In-Vitro Antioxidant Methods: Comparisons, Correlations and Considerations. International Journal of PharmTech Research, 2(2): 1276-1285 pp.

Budhiyanti, S.A., S. Raharjo, D.W. Marseno, and I.Y.B. Lelana. 2012. Antioxidant Activity of Brown Algae Sargassum Species Extract 
from the Coastline of Java Island. American Journal of Agricultural and Biological Sciences, 7(3): 337-346 pp.

Burton, W., and U. Inglod. 1984. $\beta$-Carotene: An Unusual Type of Lipid Antioxidant. Science, 224: 569-573 pp.

Devi, G.K., K. Manivannan, G. Thirumaran, F.A.A. Rajathi, dan P. Anantharaman. 2011. In Vitro Antioxidant Activities of Selected Seaweeds from Southeast Coast of India. Journal of Tropical Medicine, 205-211 pp.

Djapiala, F.Y., Lita, Montolalu, A.D.Y., dan Mentang, F. 2011. Kandungan Total Fenol dalam Rumput Laut Caulerpa racemosa yang Berpotensi sebagai Antioksidan. Unsrat.

Fitri, N. 2013. Butylated hydroxyanisole sebagai Bahan Aditif Antioksidan pada Makanan dilihat dari Perspektif Kesehatan. Jurnal Kefarmasian Indonesia, 4(1): 41-50 hlm.

Hsieh, Y.P., Suzuki, T., Wang, W., and Yoshie, Y. 2002. Compositional Difference of Phenolic Compounds between Two Seaweeds, Halimeda spp.. Journal of Tokyo University of Fisheries, 88: 21-24 pp.

Indriani, H., dan Sumiarsih, E. 1997. Budidaya, Pengolahan dan Pemasaran Rumput Laut. Indonesia.

Kang, C., Jin, B., Lee, H., Cha, M., Sohn. E., Moon, J., Park, C., Chun, S., Jung, E., Hong, J.S., Kim, J., and Kim, E. 2010. Brown algae Eclonia cava attenuates type 1 diabetes by activating AMPK and AKT signaling pathways. Journal of Food Chemistry and Toxicology, 48: 509-516 pp.

Lichtenthaler, H.K. 1987. Chlorophylls and Carotenoids: Pigments of Photosynthetic Biomembranes Methods in Enzimology. Weinheim: Verlag Chemie.

Lim, S.N., Cheung, P.C., Ooi, V.E., and Ang, P.O. 2002. Evaluation of Antioxidative Activity of Extracts from A Brown Seaweed, Sargassum siliquastrum. J. Agric Food Chem., 50(13): 3862-3866 pp.

Mardawati, E., F. Fitry, dan M. Herlina. 2008. Kajian Aktivitas Antioksidan Ekstrak Kulit Manggis (Garcinia Mangostana L) dalam Rangka Pemanfaatan Limbah Kulit Manggis di Kecamatan Puspahiang Kabupaten Tasikmalaya. Fakultas Teknologi Industri. Universitas Padjajaran. 
Marquez, U.M.L., Barros, R.M.C., and Sinnecher, R.P. 2005. Antioxidant Activity of Chlorophylls and Their Derivates. Departement of Food and Experimental Nutrition. Brazil.

Miliauskas, G., P.R. Venskutonis, and T.A. Van-Beek. 2004. Screening of Radical Scavenging Activity of Some Medical and Aromatic Plant Extracts. Food Chemistry, 85: 231-237 pp.

Młodzińska, Ewa. 2009. Survey of Plant Pigments: Molecular and Environmental Determinants of Plant Colors. Acta Biologica Cracoviensia Series Botanica, 51(1): 7-16 pp.

Munifah, I., dan W. Likanta. 2006. Senyawa Antioksidan Karoten Bersumber dari Biota Laut. Jurnal squalen, 1(1): 1-5 hlm.

Nawaly, H., Susanto, A.B., dan Uktolseja, L.A. 2013. Senyawa Bioaktif dari Rumput Laut sebagai Antioksidan. Seminar Nasional X Pendidikan Biologi FKIP UNS, Solo.

Ndhalala, A.R., M. Moyo, and J.V. Staden. 2010. Natural Antioxidants: Fascinating or Mythical Biomolecules ?. Molecules, 15: 6905-6930 pp.

Santoso, J., S. Anwariyah, R.O. Rumiantin, A.P. Putri, N. Ukhty, and Y. Yoshie Stark. 2012. Phenol Content, Antioxidant Activity and Fibers profile of Four Tropical Seagrasses from Indonesia. Journal of Coastal Development, 15(2): 189-196 pp.

Sarastani, D., S.T. Soekarto, T.R. Muchtadi, D. Fardiaz, dan A. Apriyantono. 2002. Aktivitas Antioksidan Ekstrak dan Fraksi Ekstrak Biji Antung (Parinarium glaberrimum). Jurnal Teknologi dan Industri Pangan, 13(2): 149-156 hlm.

Sayuti, K., dan Yenrina, R. 2015. Antioksidan Alami dan Sintetik. Andalas University Press, Padang, 112 hlm.

Septiana, A.T., dan Asnani, A. 2013. Aktivitas Antioksidan Ekstrak Rumput Laut Sargassum duplicatum. Jurnal Teknologi Pertanian, 14(2): 79-86 hlm.

Sheikh, T.Z.B., C.L. Yong, and M.S. Lian. 2009. In Vitro Antioxidant Activity of The Hexane and Methanolic Extract of Sargassum baccularia and Cladophora patentiramea. Journal of Applied Science, 13(9): 2490-2493 pp. 
Stahl, W., and Sies, H. 2003. Antioxidant Activity of Carotenoids. Molecular Asfects of Medicine, 24: 345-351 pp.

Sugiyono. 2005. Metode Penelitian Kualitatif. Bandung: Alfabeta.

Widayanti, N. P., Rita, W. S., dan Ciawi, Y. 2013. Pengaruh Konsentrasi Amonium Sulfat $\left(\left(\mathrm{NH}_{4}\right)_{2} \mathrm{SO}_{4}\right)$ sebagai Sumber Nitrogen Terhadap Produksi Bioetanol Berbahan Baku Gracilaria sp.. Universitas Udayana, Bali.

Wijaya, A. 1996. Radikal Bebas dan Parameter Status Antioksidan. Forum Diagnosticum. Laboratorium Klinik Prodia, 1: 1-12 hlm.

Wikanta, T., H.D. Januar, dan M. Nursed. 2005. Uji Aktivitas Antioksidan, Toksisitas dan Sitoksisitas Ekstrak Alga Merah Rhodymenia palmate. Jurnal Penelitian Perikanan Indonesia, 11(4):41-49 hlm.

Winarsi, H. 2007. Antioksidan Alami dan Radikal Bebas. Kanisius, Yogyakarta.

Wirakusumah, E.S. 2007. 202 Jus buah dan Sayuran. Cetakan 1. Jakarta: Penebar Swadaya, vi: $186 \mathrm{hlm}$.

Yangthong, M., N. Hutadilok-Towatana, and W. Phromkunthong. 2009. Antioxidant Activities of Four Edible Seaweeds from The Southern Coast of Thailand. Plant Food Human Nutrition, 64: 218-223 pp. 